\title{
Morphometric Analysis of Connective Tissue Sheaths of Sural Nerve in Diabetic and Nondiabetic Patients
}

\author{
Braca Kundalić, ${ }^{1}$ Slađana Ugrenović, ${ }^{1}$ Ivan Jovanović, ${ }^{1}$ \\ Natalija Stefanović, ${ }^{2}$ Vladimir Petrović, ${ }^{3}$ Jasen Kundalić, ${ }^{4}$ Vesna Stojanović, ${ }^{1}$ \\ Vladimir Živković, ${ }^{1}$ and Vladimir Antić ${ }^{2}$ \\ ${ }^{1}$ Department of Anatomy, Faculty of Medicine, University of Niš, Boulevard Dr. Zoran Đindić 81, 18000 Niš, Serbia \\ ${ }^{2}$ Chair of Medical Subjects, Faculty of Sport and Physical Education, University of Niš, Čarnojevićeva Street 10A, 18000 Niš, Serbia \\ ${ }^{3}$ Department of Histology and Embryology, Faculty of Medicine, University of Niš, Boulevard Dr. Zoran Đinđić 81, 18000 Niš, Serbia \\ ${ }^{4}$ Faculty of Medicine, University of Niš, Boulevard Dr. Zoran Đinđić 81, 18000 Niš, Serbia
}

Correspondence should be addressed to Braca Kundalić; brckndlc@gmail.com

Received 23 February 2014; Revised 13 June 2014; Accepted 27 June 2014; Published 24 July 2014

Academic Editor: Alfredo Conti

Copyright (c) 2014 Braca Kundalić et al. This is an open access article distributed under the Creative Commons Attribution License, which permits unrestricted use, distribution, and reproduction in any medium, provided the original work is properly cited.

One of the most common complications of diabetes mellitus is diabetic neuropathy. It may be provoked by metabolic and/or vascular factors, and depending on duration of disease, various layers of nerve may be affected. Our aim was to investigate influence of diabetes on the epineurial, perineurial, and endoneurial connective tissue sheaths. The study included 15 samples of sural nerve divided into three groups: diabetic group, peripheral vascular disease group, and control group. After morphological analysis, morphometric parameters were determined for each case using ImageJ software. Compared to the control group, the diabetic cases had significantly higher perineurial index $(P<0.05)$ and endoneurial connective tissue percentage $(P<0.01)$. The diabetic group showed significantly higher epineurial area $(P<0.01)$, as well as percentage of endoneurial connective tissue $(P<0.01)$, in relation to the peripheral vascular disease group. It is obvious that hyperglycemia and ischemia present in diabetes lead to substantial changes in connective tissue sheaths of nerve, particularly in peri- and endoneurium. Perineurial thickening and significant endoneurial fibrosis may impair the balance of endoneurial homeostasis and regenerative ability of the nerve fibers. Future investigations should focus on studying the components of extracellular matrix of connective tissue sheaths in diabetic nerves.

\section{Introduction}

Diabetic polyneuropathy is the most common neurological complications of diabetes mellitus. More than $80 \%$ of patients with diabetic neuropathy have developed distal symmetrical diabetic neuropathy (DSDN) [1], which is length dependent, due to early onset in the longest nerve fibers which are situated in the feet, then affecting more proximal parts of the lower limbs and distal parts of upper limbs eventually. This form of polyneuropathy affects at least $50 \%$ of diabetic patients and is the leading cause of foot amputation [2]. One of the major chronic diabetic complications involving diabetic neuropathy, retinopathy, and nephropathy is microangiopathy [3]. Abnormalities reported in diabetic neuropathy include axonal degeneration in nerve fibers, primary demyelination resulting from Schwann cell dysfunction, secondary segmental demyelination related to impairment of the axonal control of myelination, remyelination, proliferation of Schwann cells, atrophy of denervated bands of Schwann cells, onion-bulb formations, and hypertrophy of the basal lamina [4]. Morphological alterations of endoneurial microvessels have been described in chronic ischaemic/hypoxic neuropathy, for example, diabetic neuropathy [5-7]. In diabetic nerves, microvascular changes precede the development of neuropathy and are related to the severity of neuropathy, although their implications and roles in the development of neuropathy remain uncertain [8]. Peripheral neuropathy can also be caused by nondiabetic peripheral vascular disease in chronically ischaemic limbs [9]. 
Three connective tissue sheaths of peripheral nerves, epi-, peri-, and endoneurium are continuation of the dura mater, arachnoid mater, and pia mater, respectively. In addition to protecting the nerve fibers from compression and stretching, these layers of connective tissue also have a distinct role in providing optimal environment for the normal function and regeneration of nerve fibers. The epineurium is the outermost connective tissue sheath that surrounds peripheral nerve. The vasa nervosum enters the epineurium branching to the network of arterioles and venules which, within perineurium, penetrate into fascicles [10]. The perineurium is part of the connective tissue layers of the peripheral nerve which surrounds and protects nerve fascicles. It is a lamellated structure made up of concentric layers which are separated by interlamellar clefts rich with collagen fibrils [11]. Histochemical studies showed a variety of phosphorylating enzymes inside perineurial cells which have a high level of ATPase activity. Therefore the perineurial cells make no simple passive restrictive barrier but a metabolically active diffusion barrier [12]. Endoneurium is the innermost connective tissue sheath that covers and supports individual nerve fibres within the fascicle. Nerve fibers appear to be hermetically sealed between basement membrane of endoneurial capillaries and lamellar perineurial sheath, so that each change in neural layers may influence their function and process of regeneration. Therefore the aim of our study was to perform morphological and morphometric analysis of epi-, peri-, and endoneurial sheaths of sural nerve in diabetic patients.

\section{Materials and Methods}

The examination was carried out on 15 sural nerves routinely dissected at the Institute of Forensic Medicine, Niš, and after below-knee and above-knee amputations at the Vascular Surgery Clinic, Clinical Centre Niš. The samples of sural nerve were taken in each subject in the following way: $5 \mathrm{~cm}$ long skin cut was made between lateral malleolus and calcaneal tendon; after removal of outer skin layer and subcutaneous tissues $3 \mathrm{~cm}$ long part of sural nerve trunk was harvested and afterwards fixed in 10\% neutral-buffered formalin for 24 hours within 1 hour after surgical removal. The specimens were embedded in paraffin using standard procedures. Serial transverse sections were $5 \mu \mathrm{m}$ thick and cut on a microtome with a disposable blade for hematoxylineosin and Masson's trichrome staining.

All samples are divided into 3 groups, 5 cases each. Mean age between groups was not significant. The first group consisted of patients with type II diabetes (mean age $70 \pm 12$ years), with a range of disease duration from 8 to 20 years. Effects of diabetic neuropathy were the reason for surgical lower limb amputation. The patients diagnosed as having peripheral vascular disease (PVD) were in the second group (mean age $75 \pm 3$ years). The amputations were performed due to the lower limb and foot ulcerations and necrosis, with a history of vascular reconstruction. Control group consisted of tissue samples obtained postmortem, within $12 \mathrm{~h}$ of death. All the patients (mean age $72 \pm 8$ ) had no type II diabetes or PVD in the medical history.
Morphologic analysis of all sections is done by microscope "Olympus C011" after checking for artifacts and pathologic appearance under light microscopy. We investigated number and morphology of fasciculi, epineurial and perineurial sheath, and endoneurial content. Afterwards the images were made using $\times 40, \times 100$, and $\times 1000$ objective on 5-megapixel colour digital microscopy camera. The images were used for morphometric analysis by ImageJ image analyzing software (http://rsb.info.nih.gov/ij/). Prior to every measurement spatial calibration is done using object micrometer $(1: 100)$ for every magnification. At the lowest magnification values of total nerve cross-sectional area are measured, as well as total fascicular and total epineurial area (Figure 1). Taking into consideration that there are literature data $[13,14]$ about the influence of fascicle's size on perineurial thickness, we also measured outer (distance between two spots on the opposite sides of outer perineurial surface which pass through the center of fascicule $-D_{\mathrm{O}}$ ) and inner (distance between opposite two spots on the inner perineurial surface which pass through the center of the fascicule- $D_{I}$ ) diameter of the measured fascicles in order to calculate perineurial index $(\mathrm{P}$ index $)$ according to the formula $\mathrm{P}$ index $=\left[\left(D_{\mathrm{O}}-\right.\right.$ $\left.\left.D_{I}\right) / D_{O}\right] \times 100[15]$ (Figure 2). At the highest magnification we measured endoneurial connective tissue on 10 randomly chosen areas of great number of fasciculi for every examined case (Figures 3(a), 3(b), and 3(c)). Analysis is done using the option Image/Adjust/Color Threshold, sampling the colour at minimum three points. After converting the image to binary, we used the option Measure to calculate the area fraction on the examined areas. A total mean endoneurial connective tissue area was then calculated for each case (Figures 3(d), 3(e), and 3(f)).

\section{Statistical Methods}

To test the difference in mean values for statistical significance, we used Student's $t$-test for small independent sample, ANOVA, and Tukey's post hoc test. This was done using SPSS for Windows version 20 .

\section{Results}

After morphometric analysis we observed that the highest mean value of total neural and epifascicular area was in the diabetic group (Table 1), which was significant in comparison to nondiabetic PVD group $(P<0.05$ and $P<0.01$, resp.). The control group showed higher values of all areas comparing to PVD group but no significance (Figure 4).

After quantitative analysis using Tukey's post hoc test, the results showed that there were significantly higher values of perineurial index in both diabetic and PVD groups comparing to control group $(P<0.05$ and $P<0.01$, resp.) (Table 1). There was small difference between diabetic and nondiabetic group which showed no significance (Figure 5).

The relationship between percentages of endoneurial connective tissue was examined using Tukey's post hoc test. Our measurements showed that the highest percentage of connective tissue was present in diabetic group, and it was 


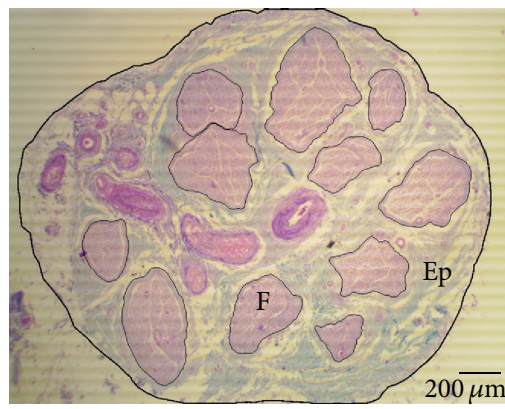

(a)

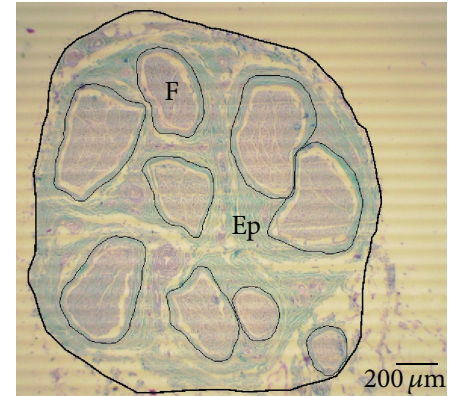

(b)

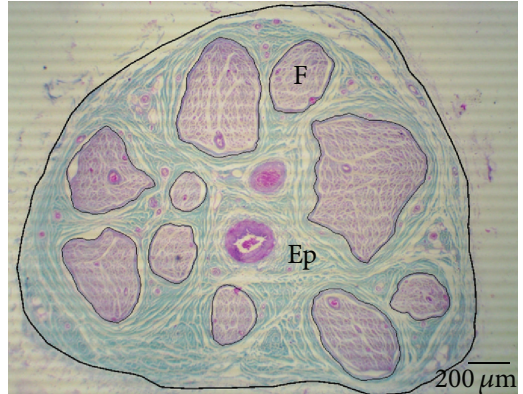

(c)

FIGURE 1: Cross section of sural nerve of diabetes group (a), PVD group (b), and control group (c). Outer contour of total nerve cross-sectional area and every fascicle area is rounded with black line. F: fascicle, Ep: epineurium; 40x lens magnification. Masson's trichrome staining.

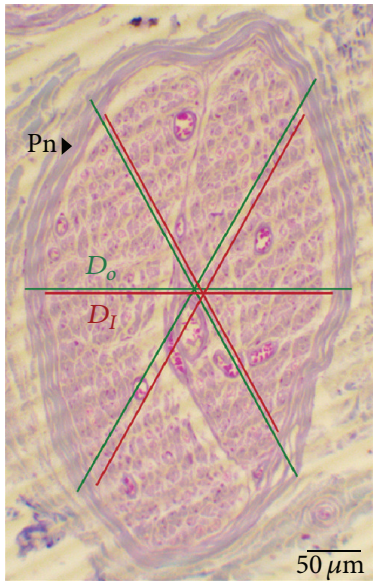

(a)

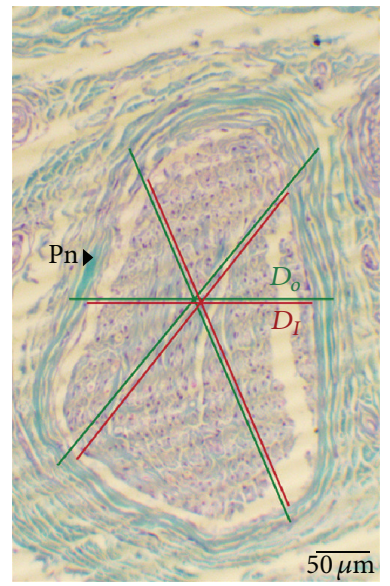

(b)

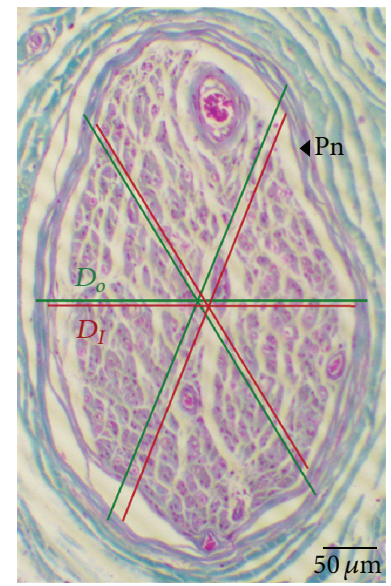

(c)

Figure 2: Cross section of sural nerve fascicle in diabetes group (a), PVD group (b), and control group (c). The image measurement of outer $\left(D_{\mathrm{O}}\right)$ and inner diameter of the fascicle $\left(D_{I}\right)$ is marked with lines at three different points; Pn: perineurium; 100x lens magnification. Masson's trichrome staining.

significantly higher than in PVD $(P<0.001)$ and control group $(P<0.01)$ (Table 1). Comparison between PVD group and control group showed no significance (Figure 6).

\section{Discussion}

Being the outermost layer of nerve, the epineurium is most prone to the macrovascular changes that happen in diabetes and peripheral vascular disease. Those changes are identified as occlusion of blood vessels and thrombosis and consequently impaired nerve blood flow, hypoperfusion, endothelial duplication, basement membrane thickening, and intima cells proliferation $[15,16]$. Tesfaye et al. [17] investigated epineurial blood vessels in sural nerves of diabetic patients and found arteriolar attenuation with venous tortuosity and distension. They confirmed the presence of active epineurial arteriovenous shunting in diabetic subjects that may result in reduction of endoneurial blood flow. Llewelyn et al. [18] reported inflammatory reaction in epineurial vessels of cutaneous nerve of the thigh in diabetic neuropathy. Beside blood vessels, lymphatic vessels may also occur in higher number as a result of the increase of epineurial vascularization. Recent study of Agliano et al. [19] showed that epineurial lymphatics may also be dilated and replete with mononuclear cells as a result of chronic inflammation or ischemia. Our findings suggest that there is difference in epineurial compartment in diabetic nerves compared to those suffering vascular changes. Significant greater amount of connective tissue may be explained with metabolic disorders that are present in hyperglycemic state which consequently provoke inflammation which, being chronic, induces fibrotic response and excess production and deposition of proteins of extracellular matrix, while in PVD blood vessels they are occluded which leads to ischemia and cell atrophy.

Our analysis shows that there is significant higher perineurial index in both diseased groups compared to control one. Higher perineurial index indicates that thickening of perineurial ensheathment is present in diabetes and peripheral vascular disease cases. The study of El-Barrany et al. [20] showed several ultrastructural changes in the basement membrane of the perineurial cells of the diabetic nerves 


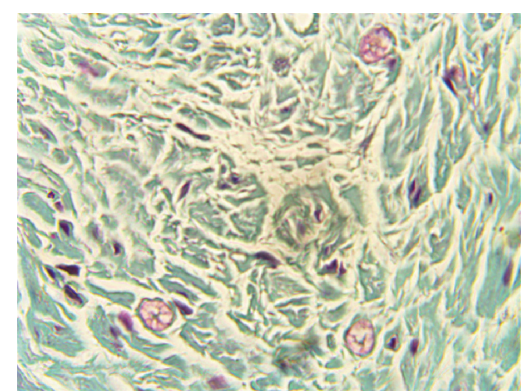

(a)

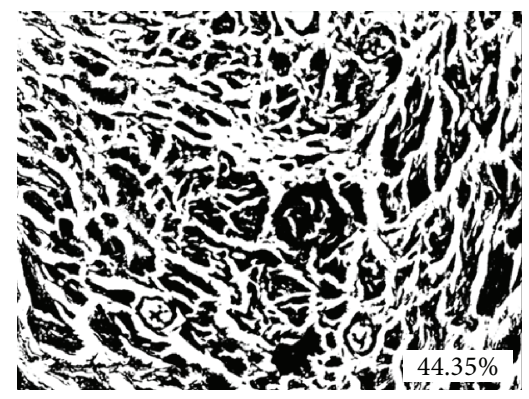

(d)

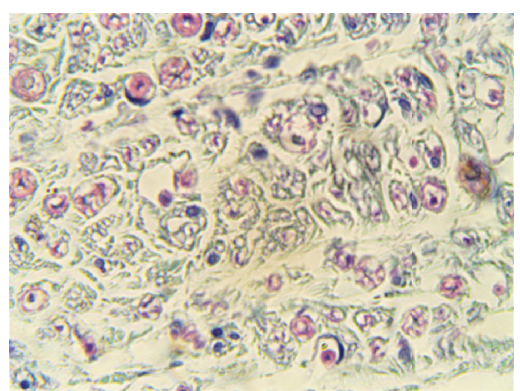

(b)

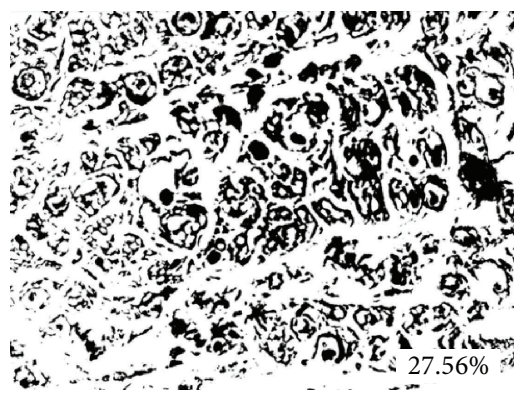

(e)

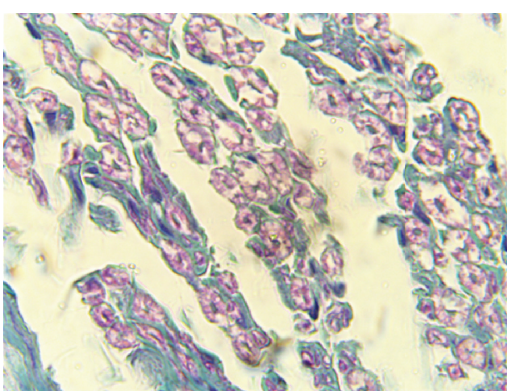

(c)

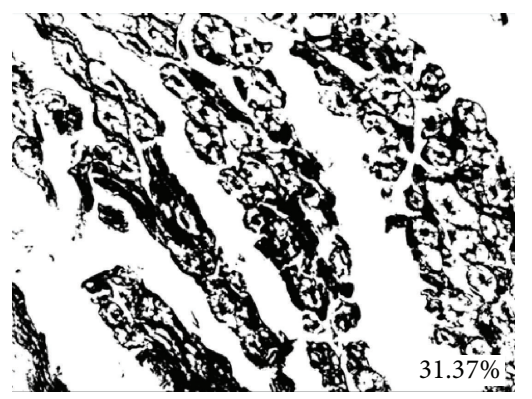

(f)

FIGURE 3: Quantification method for percentage of endoneurial connective tissue of sural nerve in diabetes group ((a) and (d)), PVD group ((b) and (e)), and control group ((c) and (f)); 1000x lens magnification. Masson's trichrome staining ((a), (b), and (c)).

TABLE 1: Results of morphometric analysis of sural nerve in diabetes, PVD, and control group.

\begin{tabular}{lccc}
\hline Group & Diabetic patients & PVD patients & Control \\
\hline Number of cases & 5 & 5 & 5 \\
Mean age & $70 \pm 12$ & $75 \pm 3$ & $72 \pm 8$ \\
Mean number of fasciculi & $10.6 \pm 4.7$ & $7.4 \pm 1.7$ & $8.6 \pm 2.7$ \\
Total nerve cross section area $\left(\mu \mathrm{m}^{2}\right)$ & $3.01 \times 10^{6} \pm 0.24 \times 10^{6^{* *}}$ & $2.1 \times 10^{6} \pm 0.3 \times 10^{6}$ & $2.678 \times 10^{6} \pm 0.57 \times 10^{6}$ \\
Total fascicular area $\left(\mu \mathrm{m}^{2}\right)$ & $0.93 \times 10^{6} \pm 0.4 \times 10^{6}$ & $0.69 \times 10^{6} \pm 0.06 \times 10^{6}$ & $0.804 \times 10^{6} \pm 0.19 \times 10^{6}$ \\
Total epineurial area $\left(\mu \mathrm{m}^{2}\right)$ & $2.08 \times 10^{6} \pm 0.39 \times 10^{6 *}$ & $1.41 \times 10^{6} \pm 0.33 \times 10^{6}$ & $1.874 \times 10^{6} \pm 0.55 \times 10^{6}$ \\
P index & $10.49 \pm 2.86^{\dagger}$ & $10.70 \pm 3.52^{\dagger}$ & $5.54 \pm 1.05$ \\
Percentage of endoneurial connective tissue & $42.22 \pm 1.76^{* * *+\dagger}$ & $29.66 \pm 5.57$ & $30.37 \pm 2.67$ \\
\hline
\end{tabular}

${ }^{*} P<0.05$ versus PVD.

${ }^{* *} P<0.01$ versus PVD.

${ }^{* * *} P<0.01$ versus PVD.

${ }^{\dagger} P<0.05$ versus control.

${ }^{\dagger \dagger} P<0.01$ versus control.

such as thickening. It also showed increased vacuoles and pinocytotic vesicles in the cellular layers of the perineurium. Consequently, these changes may suggest that permeability of the blood-nerve barrier was increased in the diabetic group. Hyperglycemia, which is the major metabolic abnormality of diabetes, has been shown to produce an upregulation of several major basement membrane components, including collagen IV and fibronectin [21, 22]. Hill and Williams [21, 23] detected with electron micrographs significantly thicker perineurial basement membrane of sural nerve in diabetic group compared to control one, but immunohistochemical analysis did not confirm that the thickening is caused by increased expression of collagen type IV, laminin, and fibronectin. In continuation of previous studies Hill [24] analyzed the presence of laminin, tenascin, and collagen types IV, V, and VI both in perineurium and in endoneurium of diabetic and nondiabetic cases. In this study the aforesaid author detected only significantly higher presence of collagen type VI in the perineurium of diabetic cases. It is apparent that finding the cause of thickening of the perineurial layer in diabetic cases needs further investigations.

Hyperglycemia is responsible for inducing oxidative stress and the polyol pathway. Higher levels of sorbitol and, consequently, fructose produced through polyol pathway are associated with impaired regulation of protein kinase $\mathrm{C}$ and $\mathrm{Na}^{+} / \mathrm{K}^{+}$-ATPase which leads to nerve dysfunction [25]. Excess glucose reacts with proteins forming advanced glycation end products (AGEs). Prime targets are proteins of 


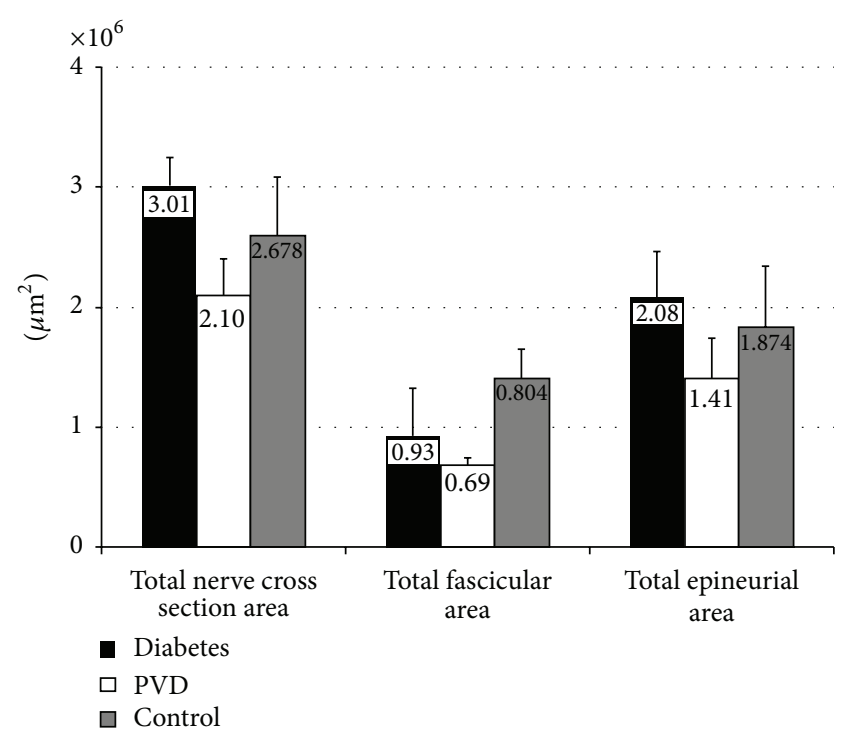

FIGURE 4: Graphic overview of mean value of total nerve crosssectional area, fascicular area, and epineurial area of sural nerve in diabetes, PVD, and control group.

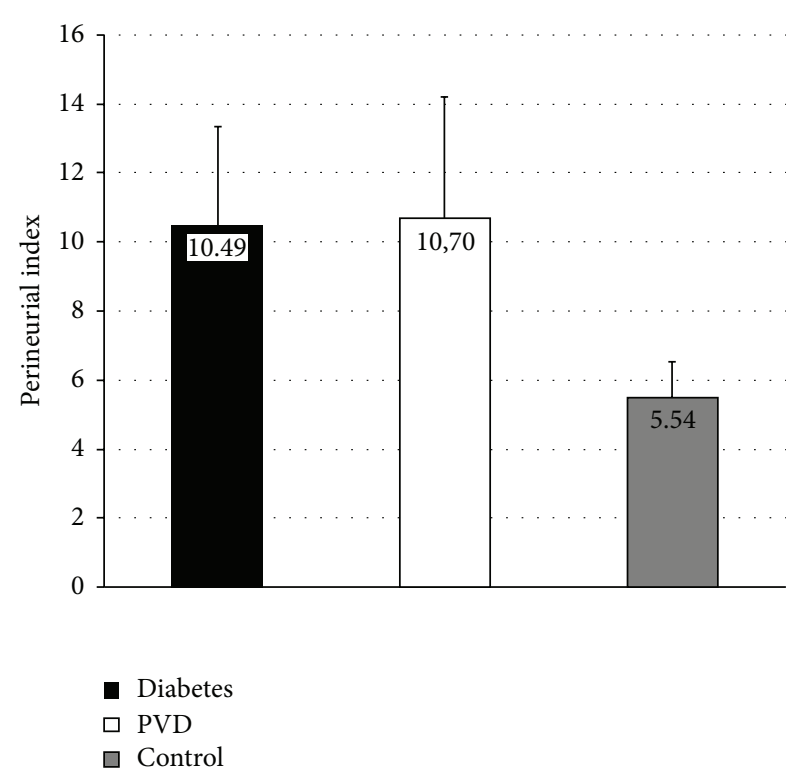

FIGURE 5: Graphic overview of mean value of perineurial index of sural nerve in diabetes, PVD, and control group.

extracellular matrix, particularly basement membrane proteins, such as types I, III, IV, and VI collagen, fibronectin, and laminin $[26,27]$. Accumulation rate of AGEs is accelerated by hyperglycemia and they are shown in various organs, such as kidney, retina, heart, or atherosclerotic plaques $[26,28]$. Clinical and experimental studies showed increased endoneurial collagen, reduplication of basement membranes around endoneurial capillaries, and thickening of basal lamina [29, 30]. Tubulin and neurofilament in the axons and myelin protein in Schwann cells may be modified by AGEs in nerve fibers, while collagen, laminin, and fibronectin were shown to

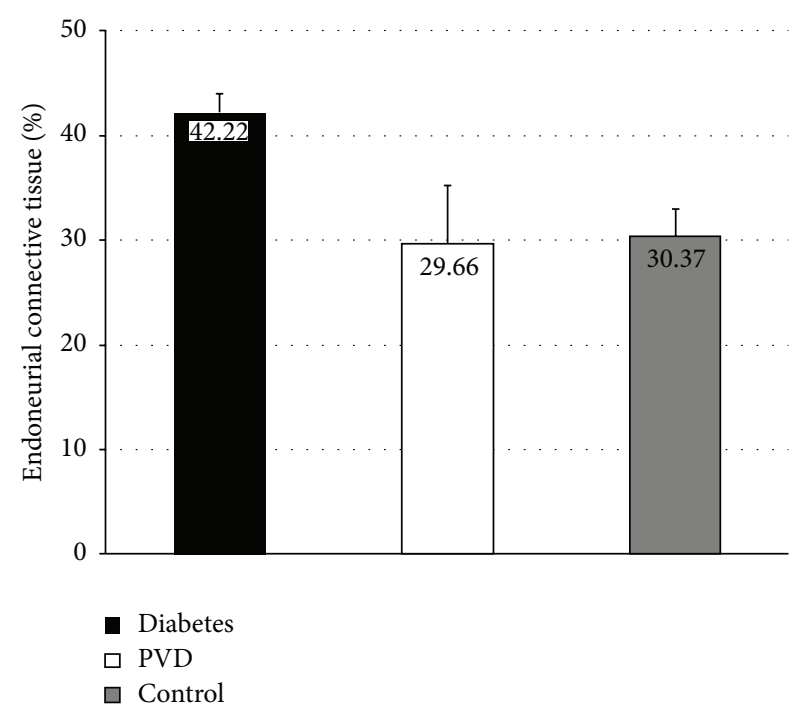

FIGURE 6: Graphic overview of mean value of endoneurial connective tissue of sural nerve in diabetes, PVD, and control group.

be glycated in basement membrane and extracellular matrix [31]. Glycated laminin and fibronectin have been shown to be responsible for failure of axonal regeneration in rat diabetic sciatic nerves and decreased ability of rat sensory neurons to extend axons [32]. Regeneration of axons may be noticed alongside degenerating neurites in uninjured diabetic nerves, but with disease progressing a number of regenerating axons declines [33], which was also observed after sural nerve biopsy [34]. Recent findings showed no significant change in levels of laminin and collagen IV in the endoneurium of diabetic nerves, but upregulation of tenascin and types $V$ and VI collagen in response to hyperglycemia was confirmed [24]. Excess collagen accumulation in endoneurial compartment is harmful for nerve fibre regeneration, as collagen fibrils are deposited inside Schwann cell basal laminal tubes, which are responsible for nerve fiber elongation, and therefore may prevent axon growth [35]. In our study endoneurial fibrosis is significantly higher only in diabetic group, which is in accordance with the results and conclusions of the investigations mentioned previously.

After morphometric analysis we can conclude that diabetes cases have significant thickening of perineurial sheath, along with endoneurial fibrosis, in comparison to control group. However epineurial ensheathment is significantly thicker only in diabetes cases comparing to PVD cases. Obtained results point to remarkable remodelling of connective tissue sheaths in diabetic neuropathy which will lead our further studies to the analysis of the components of connective tissue sheaths in diabetic nerves, such as various types of collagen and also chondroitin sulfate.

\section{Conflict of Interests}

The authors declare that there is no conflict of interests regarding the publication of this paper. 


\section{Acknowledgment}

This work was supported by Grants from Ministry of Education, Science and Technological Development of Serbia (nos. 41018, 175061, and 175092).

\section{References}

[1] M. R. G. de Freitas, O. J. M. Nascimento, L. Chimelli et al., "Neuropatia diabética I. Conceito, epidemiologia, classificação, quadro clínico e eletroneuromiográfico. Estudo de 210 casos," Revista Brasileira de Neurologia, vol. 28, pp. 69-73, 1992.

[2] S. Genuth, J. Lipps, G. Lorenzi et al., "Effect of intensive therapy on the microvascular complications of type 1 diabetes mellitus," Journal of the American Medical Association, vol. 287, no. 19, pp. 2563-2569, 2002.

[3] J. Vojtková, M. Čiljaková, and P. Bánovčin, “ Diabetic microangiopathy-etiopathogenesis, new possibilities in diagnostics and management," in Microangiopathy, R. de Cristofaro, Ed., pp. 37-66, InTech, 2012.

[4] G. Said, "Diabetic neuropathy—a review," Nature Clinical Practice Neurology, vol. 3, no. 6, pp. 331-340, 2007.

[5] P. J. Dyck and C. Giannini, "Pathologic alterations in the diabetic neuropathies of humans: a review," Journal of Neuropathology and Experimental Neurology, vol. 55, no. 12, pp. 1181-1193, 1996.

[6] R. A. Malik, "The pathology of human diabetic neuropathy," Diabetes, vol. 46, no. 2, pp. S50-S53, 1997.

[7] P. K. Thomas and D. R. Tomlinson, "Diabetic and hypoglycemic neuropathy," in Peripheral Neuropathy, P. J. Dyck and P. K. Thomas, Eds., pp. 1219-1250, WB Saunders, Philadelphia, Pa, USA, 3rd edition, 1993.

[8] C. Giannini and P. J. Dyck, "Ultrastructural morphometric abnormalities of sural nerve endoneurial microvessels in diabetes mellitus," Annals of Neurology, vol. 36, no. 3, pp. 408-415, 1994.

[9] H. Nukada, G. M. Anderson, and P. D. McMorran, "Reperfusion nerve injury: pathology due to reflow and prolonged ischaemia," Journal of the Peripheral Nervous System, vol. 2, no. 1, pp. 60-69, 1997.

[10] K. S. Topp and B. S. Boyd, "Structure and biomechanics of peripheral nerves: nerve responses to physical stresses and implications for physical therapist practice," Physical Therapy, vol. 86, no. 1, pp. 92-109, 2006.

[11] P. K. Thomas, C. H. Berthold, and J. Ochea, "Microscopic anatomy of the peripheral nervous system," in Peripheral Neuropathy, P. J. Dyck and P. K. Thomas, Eds., pp. 28-91, WB Saunders, Philadelphia, Pa, USA, 3rd edition, 1993.

[12] C-H. Berthold, J. P. Fraher, R. H. M. King, and M. Rydmark, "Microscopic anatomy of the peripheral nervous system," in Peripheral Neuropathy, P. J. Dyck and P. K. Thomas, Eds., pp. 35-91, Elsevier Health Sciences, 4th edition, 2005.

[13] S. Sunderland, Nerves and Nerve Injury, Churchill Livingstone, Edinburgh, UK, 1978.

[14] H. Tohgi, H. Tsukagoshi, and Y. Toyokura, "Quantitative changes with age in normal sural nerves," Acta Neuropathologica, vol. 38, no. 3, pp. 213-220, 1977.

[15] S. Tesfaye, N. Chaturvedi, S. E. M. Eaton et al., "Vascular risk factors and diabetic neuropathy," The New England Journal of Medicine, vol. 352, no. 4, pp. 341-431, 2005.
[16] S. Ibrahim, N. D. Harris, M. Radatz et al., "A new minimally invasive technique to show nerve ischaemia in diabetic neuropathy," Diabetologia, vol. 42, no. 6, pp. 737-742, 1999.

[17] S. Tesfaye, N. Harris, J. J. Jakubowski et al., "Impaired blood flow and arterio-venous shunting in human diabetic neuropathy: a novel technique of nerve photography and fluorescein angiography," Diabetologia, vol. 36, no. 12, pp. 1266-1274, 1993.

[18] J. G. Llewelyn, P. K. Thomas, and R. H. M. King, "Epineurial microvasculitis in proximal diabetic neuropathy," Journal of Neurology, vol. 245, no. 3, pp. 159-165, 1998.

[19] M. Agliano, N. Volpi, M. Guarna et al., "Characterization of lymphatic vessels in human peripheral neuropathies," Italian Journal of Anatomy and Embryology, vol. 117, no. 2, abstract 12, 2012.

[20] W. G. El-Barrany, R. M. Hamdy, A. A. Al-Hayani, and S. M. Jalalah, "Electron microscopic study of the myelinated nerve fibres and the perineurial cell basement membrane in the diabetic human peripheral nerves," Neurosciences, vol. 14, no. 2, pp. 131-138, 2009.

[21] R. E. Hill and P. E. Williams, "A quantitative analysis of perineurial cell basement membrane collagen IV, laminin and fibronectin in diabetic and non-diabetic human sural nerve," Journal of Anatomy, vol. 201, no. 2, pp. 185-192, 2002.

[22] P. Muona and J. Peltonen, "Connective tissue metabolism in diabetic peripheral nerves," Annals of Medicine, vol. 26, no. 1, pp. 39-43, 1994.

[23] R. E. Hill and P. E. Williams, "Perineurial cell basement membrane thickening and myelinated nerve fibre loss in diabetic and nondiabetic peripheral nerve," Journal of the Neurological Sciences, vol. 217, no. 2, pp. 157-163, 2004.

[24] R. Hill, "Extracellular matrix remodelling in human diabetic neuropathy," Journal of Anatomy, vol. 214, no. 2, pp. 219-225, 2009.

[25] J. M. Tarr, K. Kaul, M. Chopra, E. M. Kohner, and R. Chibber, "Pathophysiology of diabetic retinopathy," ISRN Ophthalmology, vol. 2013, Article ID 343560, 13 pages, 2013.

[26] S. Y. Goh and M. E. Cooper, "The role of advanced glycation end products in progression and complications of diabetes," Journal of Clinical Endocrinology and Metabolism, vol. 93, no. 4, pp. 1143-1152, 2008.

[27] H. Nukada, A. M. van Rij, S. G. K. Packer, and P. D. McMorran, "Pathology of acute and chronic ischaemic neuropathy in atherosclerotic peripheral vascular disease," Brain, vol. 119, no. 5, pp. 1449-1460, 1996.

[28] K.-G. Schmidt, H. Bergert, and R. H. W. Funk, "Neurodegenerative diseases of the retina and potential for protection and recovery," Current Neuropharmacology, vol. 6, no. 2, pp. 164178, 2008.

[29] J. L. Bradley, P. K. Thomas, R. H. M. King, and P. J. Watkins, "A comparison of perineurial and vascular basal laminal changes in diabetic neuropathy," Acta Neuropathologica, vol. 88, no. 5, pp. 426-432, 1994.

[30] S. Yagihashi, "Nerve structural defects in diabetic neuropathy: do animals exhibit similar changes?" Neuroscience Research Communications, vol. 21, pp. 25-32, 1997.

[31] R. Wada and S. Yagihashi, "Role of advanced glycation end products and their receptors in development of diabetic neuropathy," Annals of the New York Academy of Sciences, vol. 1043, pp. 598-604, 2005.

[32] B. Duran-Jimenez, D. Dobler, S. Moffatt et al., "Advanced glycation end products in extracellular matrix proteins contribute to 
the failure of sensory nerve regeneration in diabetes," Diabetes, vol. 58, no. 12, pp. 2893-2903, 2009.

[33] J. L. Bradley, P. K. Thomas, R. H. M. King et al., "Myelinated nerve fibre regeneration in diabetic sensory polyneuropathy: correlation with type of diabetes," Acta Neuropathologica, vol. 90, no. 4, pp. 403-410, 1995.

[34] A. A. F. Sima, V. Bril, V. Nathaniel et al., "Regeneration and repair of myelinated fibers in sural-nerve biopsy specimens from patients with diabetic neuropathy treated with sorbinil," The New England Journal of Medicine, vol. 319, no. 9, pp. 548$555,1988$.

[35] J. L. Bradley, R. H. M. King, J. R. Muddle, and P. K. Thomas, “The extracellular matrix of peripheral nerve in diabetic polyneuropathy," Acta Neuropathologica, vol. 99, no. 5, pp. 539-546, 2000. 


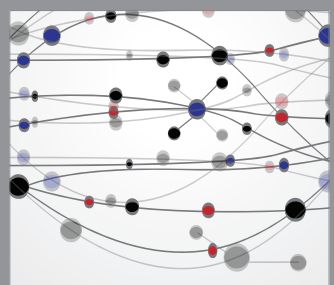

The Scientific World Journal
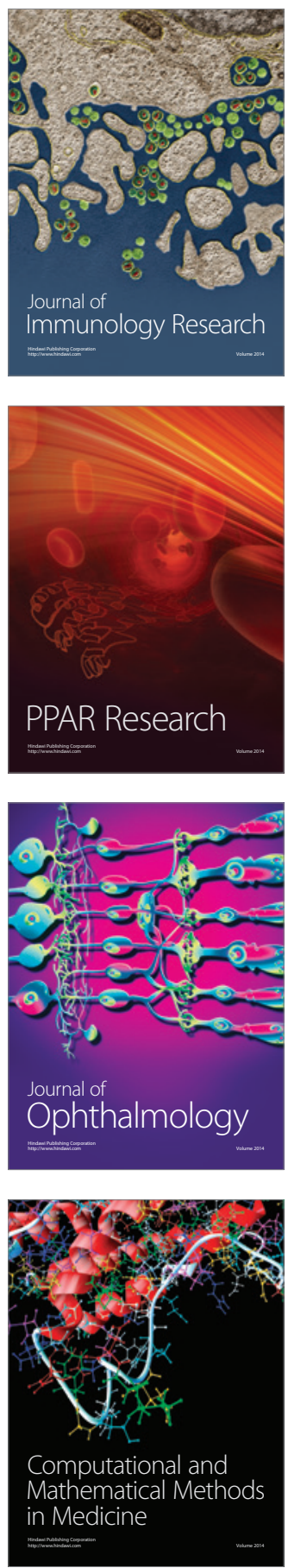

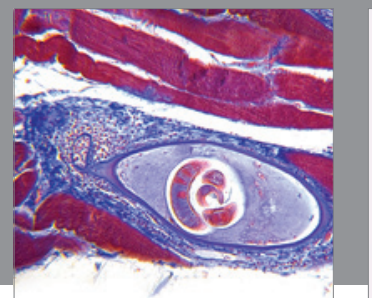

Gastroenterology

Research and Practice
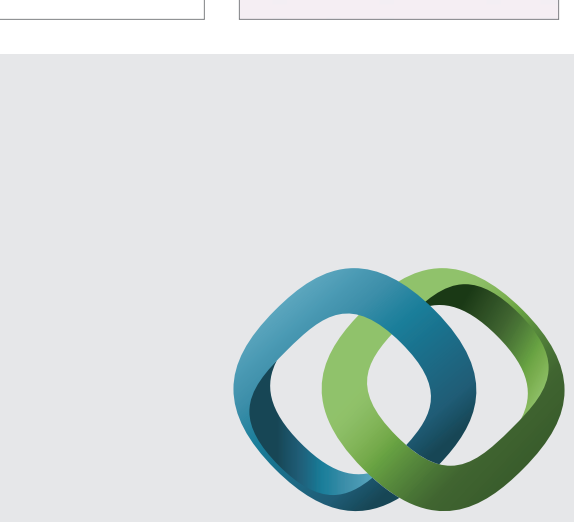

\section{Hindawi}

Submit your manuscripts at

http://www.hindawi.com
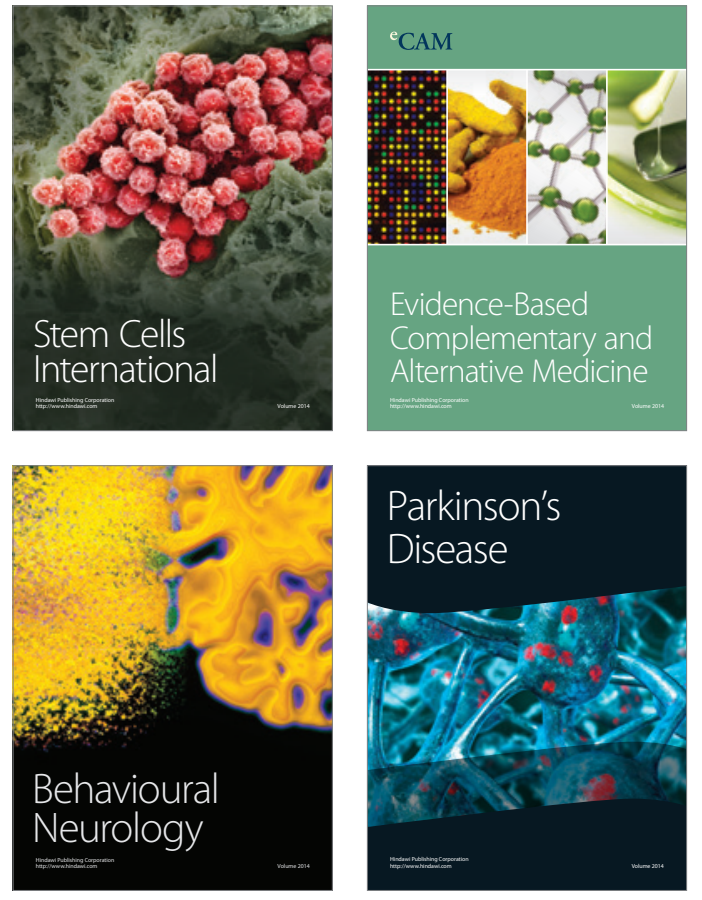
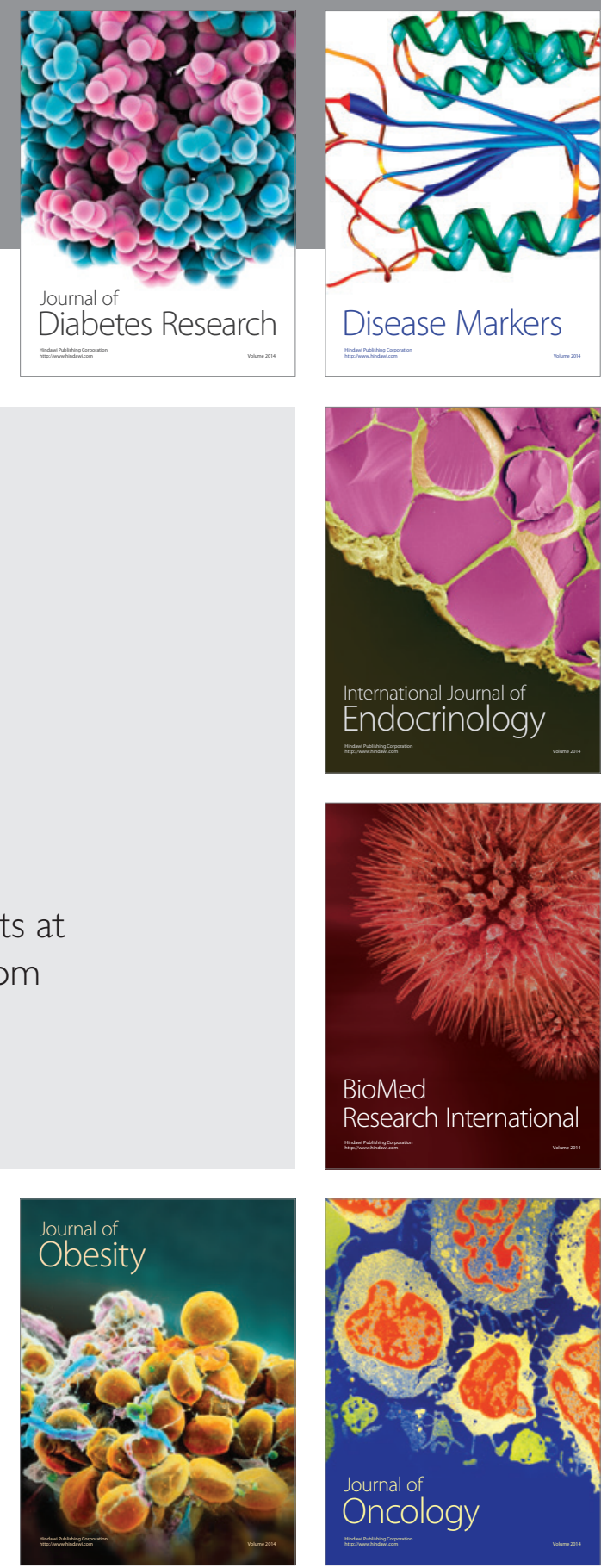

Disease Markers
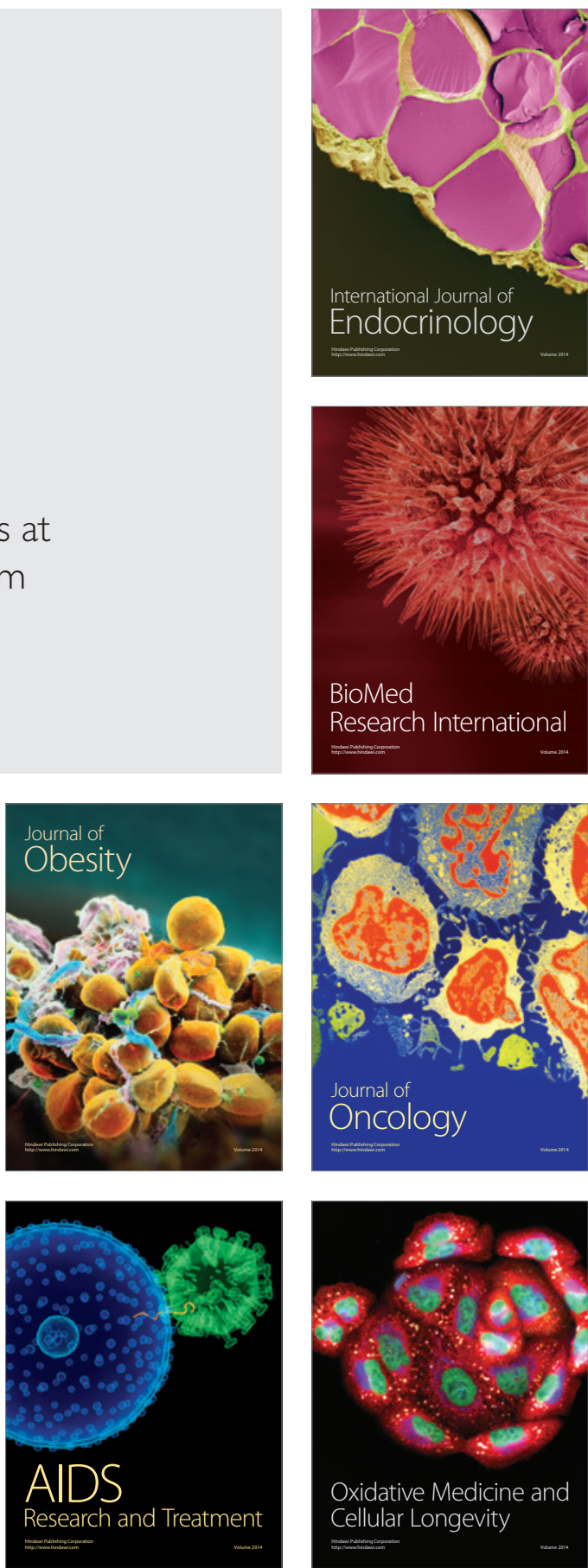